\title{
The relationship between socioeconomic position and depression among a US nationally representative sample of African Americans
}

\author{
Darrell L. Hudson • H. W. Neighbors • \\ A. T. Geronimus $\cdot$ J. S. Jackson
}

Received: 26 March 2010/ Accepted: 13 January 2011/Published online: 4 February 2011

(C) The Author(s) 2011. This article is published with open access at Springerlink.com

\begin{abstract}
Purpose Findings from previous studies have not revealed significant, inverse relationships between socioeconomic position (SEP) and depression among African Americans. This study examined the relationship between multiple indicators of SEP and Major Depressive Episode (MDE) among African Americans.

Methods Data were drawn from the National Survey of American Life main interview and re-interview. MDE, at both 12 month and lifetime intervals, was assessed using the World Mental Health version of the Composite International Diagnostic Interview. Logistic regression models were adjusted for demographics.

Results For 12-month MDE, household income and unemployment predicted greater odds of MDE among African American men, while there was an inverse relationship between education and 12-month MDE. Only unemployment was significantly associated with lifetime MDE among African American men. For African American women, a significant inverse relationship between household income and 12-month MDE was observed.
\end{abstract}

\footnotetext{
D. L. Hudson $(\bowtie)$

Center on Social Disparities in Health, Department of Family and Community Medicine, University of California at San Francisco, 3333 California Street, Suite 365, Box 0943, San Francisco, CA, USA

e-mail: hudsond@fcm.ucsf.edu
}

H. W. Neighbors - A. T. Geronimus

Department of Health Behavior and Health Education, University of Michigan, Ann Arbor, MI, USA

H. W. Neighbors · A. T. Geronimus · J. S. Jackson Institute for Social Research, University of Michigan, Ann Arbor, MI, USA
Conclusions Findings garnered from this study indicate that it is important to consider multiple measures of SEP in the prediction of depression among African Americans, and that the pattern of association between SEP and depression varies according to sex. Considering the paucity of studies that have explored the relationship between SEP and depression, additional research is needed to more firmly establish the relationship between SEP and depression. It is also important to consider stressors that may affect the relationship between SEP and depression among African Americans.

Keywords African Americans - Socioeconomic position $\cdot$ Gender $\cdot$ Depression

\section{Introduction}

A higher prevalence of depression has long been observed among poorer individuals compared to those of higher socioeconomic position (SEP) [6, 27, 28, 34]. However, results from community psychiatric epidemiologic studies largely indicate that there is no consistent inverse relationship between SEP and depression among African Americans. Williams et al. [40] found no significant relationship between SEP and rates of 6-month depression among African Americans [40]. More recently, Ennis et al. [7], using a sample of African American and White women recruited from low-income health clinics, found that income was unrelated to depression among African Americans [7]. Williams et al. [38] found no significant relationships between income or education and depression among African Americans in the National Survey of American Life (NSAL) [38]. Gavin et al. [11] found no significant relationships for African Americans between 
depression and household income, years of education, or employment status [11].

These findings are counterintuitive, considering that most physical morbidities are negatively associated with SEP indicators [20]. One potential explanation for these findings is that the SEP measurement strategies employed in most studies are inadequate. Previous studies have largely relied upon traditional SEP indicators, such as income and education with some using single-item indicators [12, 31]. Traditional SEP indicators have important limitations that should be considered when examining the SEP-depression relationship [21,36] and single-item indicators examined alone may not provide enough information about people's overall SEP. Another possible explanation is that higher SEP does not protect against the development of depression among African Americans. Farmer and Ferraro [8] described the diminishing returns hypothesis, which posits that racial/ ethnic minority groups do not experience the same economic returns associated with higher SEP achievement as Whites. Farmer and Ferraro also posited that the health differences between Whites and African Americans are greatest at the highest SEP levels because African Americans become more aware of social and economic inequalities as they ascend the socioeconomic hierarchy in the United States [2, 8]. Additionally, racial discrimination, experienced at both the interpersonal or structural level-particularly, perceptions of limited advancement in occupational settings due to racialized glass ceilings-could undermine the protective effects of higher SEP among African Americans. Two recent papers have considered the diminishing returns hypothesis in relation to mental health among racial/ethnic minority groups in the United States. Breslau et al. [2] examined whether risk of psychiatric disorders was patterned according to level of educational attainment among African Americans, Hispanics, and non-Hispanic Whites in the National Comorbidity Study Replicated. Interestingly, they found a significantly higher lifetime risk of mood disorders among African Americans with more than a high school education, compared to those with less than a high school education [2]. Conversely, Gavin et al. [11] did not find support for the diminishing returns hypothesis. They found that income and education were not related to greater odds of depression for Blacks.

Women report twice the significantly higher rates of depression of males [1, 3, 24, 26]; however, little research exists to explain this discrepancy. Nolen-Hoeksema [30] argued that women's lack of social power, their greater likelihood to experience certain stressors, such as living in poverty, or being a victim of sexual abuse, as well as the social roles that women perform, may increase their risk of depression [30]. Some researchers have argued that women may have greater reactivity than men when similarly exposed to adverse experiences and are thus more likely to develop depression than men [32]. These researchers also highlight potential neuroendocrinological pathways, such as different hormone levels among women and their greater likelihood of having a dysregulated hypothalamic-pituitary-adrenal (HPA) axis, which may increase women's vulnerability to depression $[30,32]$. There is very little information available about gender differences in depression among African Americans, or how the relationship between SEP and depression varies by gender among African Americans.

The current research

The inverse relationship between SEP and depression is one of the most universal findings in the field of psychiatric epidemiology. However, this finding does not hold true among African Americans [11, 38, 40]. Considering the fact that SEP has been implicated as a key determinant in the development of mental disorders, we examined the relationship between SEP and depression while also looking for sex differences in the SEP-depression relationship. Specifically, we examined the relationships between multiple SEP indicators (including measures of wealth and childhood SEP), in addition to traditional indicators (education, household income, and employment status), and depression among African American men and women. We were particularly interested in determining whether differences exist in the relationship between SEP and depression according to gender. Second, this study tested the diminishing returns hypothesis. Specifically, we hypothesized that African Americans, both men and women, who reported greater levels of SEP would also report increased odds of both 12-month and lifetime Major Depressive Episode (MDE).

We examined the National Survey of American Life (NSAL) to achieve the goals of this paper. The NSAL is the largest nationally representative survey of mental disorders among African Americans to date and it contains a rich array of SEP variables that are essential to our purposes. The NSAL used the World Mental Health Composite International Diagnostic Interview (WMH-CIDI) to identify cases of depression. The strong design of the study, including face-to-face interviews, matching respondents and interviewers on race, and the NSAL sampling strategy make the NSAL ideal for pursuing the study goals.

\section{Method}

Sample

Data for this paper were drawn from the NSAL, a national population-based sample drawn from the coterminous 
United States. Data were collected using a stratified and clustered sample design, and weights were created to account for unequal probabilities of selection, nonresponse, and post-stratification. More detailed documentation on the NSAL sampling methodology and study procedures are discussed elsewhere [14, 19]. The final African American sample included 3,570 African American respondents aged 18 years and over. NSAL data were collected between 2001 and 2003 and utilized an in-home, face-to-face interview design with computer-assisted personal interviewing (CAPI) software. NSAL interviews lasted an average of $2 \mathrm{~h}$ and $20 \mathrm{~min}$ [18].

In addition to the face-to-face interview, NSAL respondents were invited to complete a self-administered questionnaire, the NSAL Adult Re-interview (RIW). A total of 2,137 African Americans participated in the RIW. Among other items, respondents were asked about their housing equity and were asked to provide a dollar amount of all the assets they owned, as well as an estimate of the debts they owed. Respondents who were female, unemployed, more highly educated, and participated in the original NSAL interview post-September 11, 2001, had higher response rates on the RIW. Weights were created and used to account for non-response variations.

We restricted analysis to respondents who provided SEP information, including household income, education, employment status, wealth indicators, and mother's education, as well as to those respondents for whom the diagnosis of 12-month and lifetime MDE was available. These restrictions resulted in a final sample of 579 men and 1,050 women for 12-month MDE, and 602 men and 1,267 women for lifetime MDE.

\section{Measurement}

\section{Depression}

MDE was the outcome of interest for this study and was based upon meeting diagnostic criteria for MDE using the WMH-CIDI, a fully structured lay-administered diagnostic instrument that approximates DSM-IV diagnoses of psychiatric disorders [23, 25, 42]. A case for MDE was determined when respondents met DSM-IV criteria for MDE according to the CIDI.

\section{SEP measures}

Household income was measured by respondents' reported annual household income in US dollars and was categorized as: $<\$ 17,000 ; \$ 17,000-49,999 ; \$ 45,000-79,999$; and $\geq \$ 80,000$. Respondents' highest level of education was assessed by the following categories: $<12$ years; 12 years;
13-15 years; and $\geq 16$ years. Respondents' employment status was coded into three categories: employed, corresponding to respondents who reported that they were currently employed at the time of data collection; unemployed, for respondents who were unemployed but actively seeking employment; and not in workforce, for respondents who were not currently working and were not seeking employment. Mother's education, measured by the number of years of school completed, was used as a measure of childhood SEP.

The wealth measures examined here included net worth and estimated home value. The net worth measure was calculated by determining respondents' reported assets minus debts. To account for missing data on net worth (45\% were missing information on assets and $35 \%$ were missing information on debt) multiple imputation was carried out using the SAS multiple imputation procedure (PROC MI) based on African American respondents' sex, age, reported household income, years of education, employment status, marital status, household size, and US geographic region [43].

\section{Covariates}

Age was a continuous variable of respondents' reported age at the time of the interview. Marital status was coded into three categories (married/partnered, separated/divorced/ widowed, and never married), with married/partnered as the reference group. Geographic region included four categories (Northeast, Midwest, South, and West) with South as the reference category. Household size indicated the number of individuals residing in respondents' households, including adults and children.

Statistical analyses

Multiple logistic regression models, stratified by sex, were used to estimate the influence of SEP indicators on odds of MDE. Analyses were stratified by sex to examine differences between African American men and women.

\section{Results}

Table 1 describes the sociodemographic characteristics of the NSAL African American sample stratified by sex. African American males and females had the same average age (42.5 years), household size (2.89), and similar regional distribution and levels of education. Among males, the majority of respondents reported that they were currently employed $(71.4 \%)$, and slightly more than half $(51.1 \%)$ reported they were married or lived with a romantic partner. Among women, $63 \%$ reported that they were currently 
Table 1 Sociodemographic characteristics of African Americans in the NSAL

\begin{tabular}{|c|c|c|}
\hline & $\begin{array}{l}\text { Males }(n=693) \\
\%(\mathrm{SE}) ; \mathrm{M}(\mathrm{SE})\end{array}$ & $\begin{array}{l}\text { Females }(n=1,444) \\
\%(\mathrm{SE}) ; \mathrm{M}(\mathrm{SE})\end{array}$ \\
\hline Total & 693 & 1,444 \\
\hline \multicolumn{3}{|l|}{ Household income } \\
\hline$<\$ 17,000$ & $25.57(2.43)$ & $38.76(1.97)$ \\
\hline$\$ 17,000-44,999$ & $22.91(1.43)$ & $26.37(1.59)$ \\
\hline$\$ 45,000-79,999$ & $26.55(1.82)$ & $19.66(1.27)$ \\
\hline$>\$ 80,000$ & $24.97(2.64)$ & $15.22(1.51)$ \\
\hline \multicolumn{3}{|l|}{ Education (years) } \\
\hline$<12$ & $24.37(2.79)$ & $24.97(2.06)$ \\
\hline 12 & $34.9(2.15)$ & $37.21(1.46)$ \\
\hline $13-15$ & $24.21(2.45)$ & $25.01(1.28)$ \\
\hline$\geq 16$ & $16.52(2.30)$ & $12.81(1.19)$ \\
\hline \multicolumn{3}{|l|}{ Employment status } \\
\hline Employed & $71.41(2.06)$ & $63.19(1.91)$ \\
\hline Unemployed & $9.89(1.4)$ & $11.5(1.1)$ \\
\hline Not in labor force & $18.7(1.94)$ & $25.32(1.48)$ \\
\hline \multicolumn{3}{|l|}{ Maternal education } \\
\hline$<12$ & 34.69 (3.70) & $39.8(2.12)$ \\
\hline 12 & $38.31(2.80)$ & $36.93(2.0)$ \\
\hline $13-15$ & $13.0(2.02)$ & $11.87(1.14)$ \\
\hline$\geq 16$ & $14.1(1.50)$ & $11.41(1.18)$ \\
\hline Net worth & $90,350(5,229.08)$ & $106,278(5,046.56)$ \\
\hline Home equity & $91,186(2,886.89)$ & $77,368(1,885.30)$ \\
\hline \multicolumn{3}{|l|}{ Marital status } \\
\hline Married/partnered & $51.09(2.59)$ & $34.44(1.48)$ \\
\hline $\begin{array}{l}\text { Divorced/separated/ } \\
\text { widowed }\end{array}$ & $19.4(19.4)$ & $32.05(1.29)$ \\
\hline Never married & $29.51(2.5)$ & $33.52(1.66)$ \\
\hline Age & $42.51(0.43)$ & $42.51(0.34)$ \\
\hline Household size & $2.89(0.04)$ & $2.89(0.03)$ \\
\hline \multicolumn{3}{|l|}{ Region } \\
\hline Northeast & $15.47(1.60)$ & $13.91(1.67)$ \\
\hline Midwest & 18.55 (1.99) & $19.89(2.35)$ \\
\hline West & $9.28(1.42)$ & $7.39(1.26)$ \\
\hline South & $56.7(2.89)$ & $58.81(2.68)$ \\
\hline
\end{tabular}

employed, $34 \%$ reported that they were currently married or lived with a romantic partner. There were significant gender differences in levels of reported household income, with men reporting higher levels than women. Males reported higher home values than women, while females reported greater levels of net worth than males. African American females also reported significantly greater prevalence of both 12-month and lifetime MDE compared to males (1.98 vs. 4.83 , and 3.61 vs. 7.88 , respectively).

Tables 2 and 3 display the relationship between SEP indicators and MDE for African Americans, adjusted for
Table 2 Multivariate logistic regression of SEP indicators on 12-month Major Depressive Episode

\begin{tabular}{|c|c|}
\hline Variables & OR $(95 \% \mathrm{CI})$ \\
\hline \multicolumn{2}{|l|}{ Household income } \\
\hline \multicolumn{2}{|l|}{$<\$ 17,000$ (ref.) } \\
\hline$\$ 17,000-44,999$ & $0.66(0.33-1.32)$ \\
\hline$\$ 45,000-79,999$ & $0.65(0.29-1.47)$ \\
\hline$>\$ 80,000$ & $1.36(0.52-3.57)$ \\
\hline \multicolumn{2}{|l|}{ Education (years) } \\
\hline \multicolumn{2}{|l|}{$<12$ (ref.) } \\
\hline 12 & $0.54(0.30-0.99)$ \\
\hline $13-15$ & $0.41(0.21-0.81)^{*}$ \\
\hline$\geq 16$ & $0.47(0.18-1.26)$ \\
\hline \multicolumn{2}{|l|}{ Employment status } \\
\hline \multicolumn{2}{|l|}{ Employed (ref.) } \\
\hline Unemployed & $1.84(0.88-3.86)$ \\
\hline Not in labor force & $0.88(0.45-1.70)$ \\
\hline Maternal education & $1.05(0.99-1.11)$ \\
\hline Net worth $(\log )$ & $1.03(0.64-1.66)$ \\
\hline Home value (log) & $1.60(0.53-4.81)$ \\
\hline \multicolumn{2}{|l|}{ Marital status } \\
\hline \multicolumn{2}{|l|}{ Married/partnered (ref.) } \\
\hline Divorced/separated/widowed & $1.70(0.76-3.78)$ \\
\hline Never married & $1.89(0.91-3.89)$ \\
\hline Age & $0.99(0.97-1.01)$ \\
\hline Female & $1.80(1.01-3.21)^{*}$ \\
\hline Household size & $1.02(0.88-1.18)$ \\
\hline \multicolumn{2}{|l|}{ Region } \\
\hline Northeast & $1.07(0.56-2.06)$ \\
\hline Midwest & $1.88(1.17-3.05)$ \\
\hline West & $0.89(0.18-4.49)$ \\
\hline \multicolumn{2}{|l|}{ South (ref.) } \\
\hline Pseudo $R^{2}$ & 0.09 \\
\hline
\end{tabular}

$O R$ odds ratio, $C I$ confidence interval

* Significant at $p=0.05$ level, two-sided test

marital status, age, sex, household size, and geographic region. For both 12-month and lifetime MDE, female respondents reported significantly greater odds of depression than males. Most of the SEP variables examined here were unrelated to depression. There were several exceptions to this pattern. For 12-month MDE, we found that respondents who reported 13-15 years of education had lower odds of depression than those who reported less than 12 years. For lifetime MDE, mother's education was inversely associated with increased odds of depression.

As indicated in Table 4, male respondents in the $\$ 80,000$ and above household income category reported greater odds of depression than male respondents in the lowest income category (OR $=5.20$; CI: 1.41-19.12). In addition, unemployed male respondents reported significantly greater odds of 
Table 3 Multivariate logistic regression of SEP indicators on Lifetime Major Depressive Episode

\begin{tabular}{ll}
\hline Variables & OR $(95 \% \mathrm{CI})$ \\
\hline Household income & \\
$<\$ 17,000$ (ref.) & \\
$\$ 17,000-44,999$ & $0.73(0.45-1.18)$ \\
$\$ 45,000-79,999$ & $0.61(0.33-1.15)$ \\
$>\$ 80,000$ & $1.10(0.53-2.28)$ \\
Education (years) & \\
$<12$ (ref.) & \\
12 & $0.73(0.44-1.21)$ \\
$13-15$ & $0.59(0.33-1.06)$ \\
$\geq 16$ & $0.79(0.36-1.70)$ \\
Employment status & \\
Employed (ref.) & \\
Unemployed & $1.60(0.92-2.80)$ \\
Not in labor force & $0.92(0.57-1.49)$ \\
Maternal education & $1.06(1.01-1.12)^{*}$ \\
Net worth (log) & $1.05(0.74-1.48)$ \\
Home value (log) & $1.32(0.54-3.25)$ \\
Marital status & \\
Married/partnered (ref.) & \\
Divorced/separated/widowed & \\
Never married & \\
Age & \\
Female & \\
Household size & $1.06(0.53(0.93-2.22)$ \\
Region & $1.44(0.81-2.58)$ \\
Northeast & $0.99(0.98-1.02)$ \\
Midwest & \\
West & \\
South (ref.) & \\
\hline & \\
\hline &
\end{tabular}

$O R$ odds ratio, $C I$ confidence interval

* Significant at $p=0.05$ level, two-sided test

12-month MDE than employed male respondents $(\mathrm{OR}=3.78$; CI: 1.09-13.12). For education, male respondents in the 13-15 years and 16 or greater years categories reported lower odds of 12-month MDE than male respondents with less than 12 years of education. There was not a statistically significant relationship between maternal education and 12-month MDE. We also did not find significant relationships between either of the wealth indicators (net worth and home value) and 12-month MDE among African American males.

Among African American female respondents, there was a significant inverse relationship observed between household income and 12-month MDE. Women in the $\$ 45,000$ to $\$ 79,999$ income category reported significantly lower odds of 12-month MDE than women in the lowest income category $(\mathrm{OR}=0.33$; $\mathrm{CI}$ : $0.13-0.82)$. There were
Table 4 Multivariate logistic regression of SEP indicators on 12-month Major Depressive Episode; by sex

\begin{tabular}{|c|c|c|}
\hline Variables & $\begin{array}{l}\text { Males }(n=579) \\
\text { OR }(95 \% \mathrm{CI})\end{array}$ & $\begin{array}{l}\text { Females }(n=1,050) \\
\text { OR }(95 \% \mathrm{CI})\end{array}$ \\
\hline \multicolumn{3}{|l|}{ Household income } \\
\hline \multicolumn{3}{|l|}{$<\$ 17,000$ (ref.) } \\
\hline$\$ 17,000-44,999$ & $0.60(0.07-5.04)$ & $0.54(0.25-1.19)$ \\
\hline$\$ 45,000-79,999$ & $2.01(0.56-7.25)$ & $0.33(0.13-0.82)^{*}$ \\
\hline$>\$ 80,000$ & $5.20(1.41-19.12)^{*}$ & $0.59(0.19-1.84)$ \\
\hline \multicolumn{3}{|l|}{ Education (years) } \\
\hline \multicolumn{3}{|l|}{$<12$ (ref.) } \\
\hline 12 & $0.41(0.15-1.10)$ & $0.64(0.34-1.23)$ \\
\hline $13-15$ & $0.26(0.09-0.76)^{*}$ & $0.54(0.22-1.31)$ \\
\hline$\geq 16$ & $0.19(0.05-0.72)^{*}$ & $0.70(0.22-2.23)$ \\
\hline \multicolumn{3}{|l|}{ Employment status } \\
\hline \multicolumn{3}{|l|}{ Employed (ref.) } \\
\hline Unemployed & $4.65(1.39-15.54)^{*}$ & $1.05(0.50-2.18)$ \\
\hline Not in labor force & $0.99(0.23-4.33)$ & $0.83(0.50-1.39)$ \\
\hline Maternal education & $1.05(0.94-1.17)$ & $1.05(0.98-1.13)$ \\
\hline Net worth $(\log )$ & $0.76(0.26-2.22)$ & $1.19(0.68-2.07)$ \\
\hline Home value (log) & $1.11(0.10-12.58)$ & $2.41(0.70-8.24)$ \\
\hline \multicolumn{3}{|l|}{ Marital status } \\
\hline \multicolumn{3}{|l|}{ Married/partner (ref.) } \\
\hline $\begin{array}{l}\text { Divorced/separated/ } \\
\text { widowed }\end{array}$ & $4.42(1.11-17.57)^{*}$ & $1.18(0.58-2.39)$ \\
\hline Never married & $7.86(2.60-23.79)^{*}$ & $1.13(0.50-2.52)$ \\
\hline Age & $1.01(0.98-1.04)$ & $0.98(0.96-1.01)$ \\
\hline Household size & $1.030 .62-1.73)$ & $1.06(0.92-1.23)$ \\
\hline \multicolumn{3}{|l|}{ Region } \\
\hline Northeast & $0.22(0.02-2.52)$ & $1.52(0.66-3.54)$ \\
\hline Midwest & $1.84(0.56-6.08)$ & $2.08(1.16-3.74)$ \\
\hline West & $0.99(0.12-7.91)$ & $0.587(0.11-3.04)$ \\
\hline \multicolumn{3}{|l|}{ South (ref.) } \\
\hline Pseudo $R^{2}$ & 0.23 & 0.07 \\
\hline
\end{tabular}

$O R$ odds ratio, $C I$ confidence interval

* Significant at $p=0.05$ level, two-sided test

no significant relationships between any other SEP indicators, including education, wealth, and parental education, and 12-month MDE observed for African American women.

Table 5 displays the relationship between SEP and lifetime MDE among African Americans stratified by sex. For African American males, there were no significant relationships between SEP and lifetime odds of MDE, with the exception of unemployment. Unemployed male respondents reported significantly greater odds of lifetime depression than employed male respondents $(\mathrm{OR}=3.91$; CI: 1.41-10.82). Female respondents who reported earning $\$ 45,000-\$ 79,999$ had significantly lower odds of lifetime MDE than females who reported household incomes below 
Table 5 Multivariate logistic regression of SEP indicators on Lifetime Major Depressive Episode; by sex

\begin{tabular}{|c|c|c|}
\hline Variables & $\begin{array}{l}\text { Males }(n=602) \\
\text { OR }(95 \% \mathrm{CI})\end{array}$ & $\begin{array}{l}\text { Females }(n=1,267) \\
\text { OR }(95 \% \text { CI })\end{array}$ \\
\hline \multicolumn{3}{|l|}{ Household income } \\
\hline \multicolumn{3}{|l|}{$<\$ 17,000$ (ref.) } \\
\hline$\$ 17,000-44,999$ & $0.59(0.16-2.15)$ & $0.72(0.40-1.31)$ \\
\hline$\$ 45,000-79,999$ & $1.07(0.42-2.69)$ & $0.43(0.21-0.91)^{*}$ \\
\hline$>\$ 80,000$ & $2.50(0.85-7.35)$ & $0.65(0.26-1.65)$ \\
\hline \multicolumn{3}{|l|}{ Education (years) } \\
\hline \multicolumn{3}{|l|}{$<12$ (ref.) } \\
\hline 12 & $1.02(0.40-2.62)$ & $0.65(0.37-1.13)$ \\
\hline $13-15$ & $0.59(0.19-1.85)$ & $0.60(0.28-1.28)$ \\
\hline$\geq 16$ & $0.72(0.21-2.44)$ & $0.88(0.39-2.02)$ \\
\hline \multicolumn{3}{|l|}{ Employment status } \\
\hline \multicolumn{3}{|l|}{ Employed (ref.) } \\
\hline Unemployed & $3.91(1.41-10.82)^{*}$ & $0.95(0.54-1.67)$ \\
\hline Not in labor force & $0.85(0.30-2.42)$ & $0.93(0.57-1.51)$ \\
\hline Maternal education & $1.10(0.99-1.21)$ & $1.05(0.99-1.12)$ \\
\hline Net worth $(\log )$ & $0.78(0.34-1.78)$ & $1.20(0.80-1.78)$ \\
\hline Home value (log) & $0.68(0.11-4.16)$ & $2.05(0.66-6.40)$ \\
\hline \multicolumn{3}{|l|}{ Marital status } \\
\hline \multicolumn{3}{|c|}{ Married/partnered (ref.) } \\
\hline $\begin{array}{l}\text { Divorced/separated/ } \\
\text { widowed }\end{array}$ & $3.20(1.15-8.88)^{*}$ & $1.06(0.59-1.92)$ \\
\hline Never married & $3.60(1.48-8.79)^{*}$ & $1.02(0.49-2.14)$ \\
\hline Age & $1.03(0.99-1.05)$ & $0.99(0.97-1.01)$ \\
\hline Household size & $1.17(0.89-1.54)$ & $1.00(0.87-1.15)$ \\
\hline \multicolumn{3}{|l|}{ Region } \\
\hline Northeast & $0.82(0.20-3.44)$ & $1.69(1.01-2.83)^{*}$ \\
\hline Midwest & $1.68(0.97-2.92)$ & $1.43(0.93-2.21)$ \\
\hline West & $1.13(0.22-5.77)$ & $0.54(0.17-1.68)$ \\
\hline \multicolumn{3}{|l|}{ South (ref.) } \\
\hline Pseudo $R^{2}$ & 0.13 & 0.05 \\
\hline
\end{tabular}

$O R$ odds ratio, $C I$ confidence interval

* Significant at $p=0.05$ level, two-sided test

$\$ 17,000 \quad(\mathrm{OR}=0.43 ; 0.21-0.91)$. No other significant relationships were observed between SEP indicators and lifetime MDE among females.

Comparing the results from both 12-month and lifetime measures of MDE, only two associations between SEP and MDE remained constant. For African American men, unemployment was significantly related to increased odds of depression. African American women grouped in the $\$ 45,000-\$ 79,000$ household income category reported decreased odds of depression. Interestingly, we found that marital status was a significant factor in predicting depression among African American men, but not women. Specifically, men in the divorced/separated/widowed and never married categories reported significantly greater odds of both 12-month and lifetime MDE, compared to married men.

\section{Discussion}

It should be acknowledged that this study has several key limitations. First, the data set utilized in this study is crosssectional and, as a result, the issue of social selection versus social causation cannot be addressed. Specifically, we cannot examine whether depression caused SEP or the reverse. The observed associations between SEP and depression could be partially explained by the occurrence of depression in adolescence or early adulthood, rather than being due to more proximal events, such as income or employment status [13]. A prospective study design would be more advantageous in determining whether social disadvantage or privilege predict depression among African Americans [35]. A prospective design would also allow us to consider the effects of lifetime occurrence of depression on depressive episodes that occur later in life. Second, it is possible that the imputation method used created inaccurate estimates of wealth because the missing values for study respondents may not have been missing at random. Respondents with higher levels of wealth may have been more likely to report their financial holdings, which would artificially inflate wealth estimates in this study. Additionally, the imputation method used to derive estimates of assets and debts is based upon the SEP information that respondents did provide, such as household income, education, employment status, and home ownership. It is possible that the imputed values of net worth are not independent and simply reflect the traditional measures of SEP. Despite the complexity and difficulty in collecting accurate wealth information from study participants, the consideration of wealth effects upon depression remains an important issue and investigators must continue to develop methods to obtain complex, sensitive wealth information from study participants.

In support of our hypothesis that greater SEP would be associated with increased odds of depression, we found that higher household income was associated with greater odds of 12-month MDE among African American men. Specifically, we found that the highest earning African American men reported greater odds of depression compared to men in the lowest income category. In contrast to our hypothesis, however, African American men who reported greater levels of education had lower odds of 12-month MDE, compared to men in the lowest income category. Perhaps education is valued more highly among African American men and provides protection from depression. Conversely, higher earning African American men may encounter greater amounts of stress due to 
increased exposure to racial discrimination. For example, previous studies have indicated that African Americans who earn more money and work in more prestigious occupations are more aware of structural barriers and limitations in their work environments [5, 10, 29]. Additionally, higher earning African American men may have to address conflicts within their social networks due to decreased proximity to their social support networks, in addition to facing greater demands for social capital and even monetary assistance, compared to working class or poor African Americans [15, 16].

We found that unemployment was a significant predictor of both 12-month and lifetime MDE for men. Unemployed men reported over more than four times greater odds of depression compared to employed men. With an unemployment rate of $16.7 \%$, African American men currently have the highest rate of unemployment in the US and $8 \%$ of African American men have lost their jobs since November 2007 [4]. Considering the high number of unemployed African American men during the current economic recession, unemployment represents a substantial threat to the mental health of African American men that clinicians should note. Additionally, investigators should continue to explore the importance and impact of employment status and the ability to provide for a family as a gendered role that could affect depression among African American men.

Among female respondents, SEP did not appear to be a significant predictor of depression. Only women who were in the \$45,000-\$79,000 household income category had significantly lower odds of 12-month and lifetime MDE compared to women in the reference category, who reported household incomes less than $\$ 17,000$ a year. In future investigations of the relationship between SEP and depression, it may also be worthwhile to investigate economic stressors, rather than SEP, which may be more significant in the prediction of depression among African American women.

It is important to note that no significant relationships were observed between wealth indicators, measured by net worth and home value, and depression among African Americans. This finding is similar to results garnered from previous studies that found no relationship between markers of wealth and indices of mental health for African Americans [33]. However, as was mentioned, it is possible that the method used to measure and impute net worth in this study precluded the observation of the relationship between net worth and depression. Considering the small number of studies that have examined the relationship between indices of wealth and depression among African Americans, more studies are needed before reaching a conclusive understanding of the wealth-depression relationship. Additionally, a prospective design may help researchers to understand how the interaction of wealth (or the lack of it) with life stressors could affect the mental health of individuals over time.

While we did not form hypotheses a priori, it is clear that marital status is a significant factor in predicting depression among African Americans, and the effects of marital status vary across sex. Among African American men, respondents in the divorced/separated/widowed and never married categories demonstrated over four and seven times greater odds, respectively, of depression than married men. These findings indicate that marriage may be a protective factor against the development of depression among African American men. This finding could also indicate another social selection issue, as men who suffer from depression could be less likely to get married or could be more likely to get divorced or separated. Conversely, marital status was not related to decreased odds of depression among African American women. Scholars have argued that women may place more emphasis on caring for others, rather than for themselves, and that marital satisfaction has a larger effect upon depression for women than men [9]. These findings indicate that the effect of marriage, including marital satisfaction and discord, upon depression among African American men and women warrants further examination in future work.

The results presented here do not offer conclusive evidence of a uniform positive or negative relationship between SEP and depression among African Americans. However, the findings of this study are important because they highlight patterns of association between SEP and depression, as well as between marital status and depression, that vary by sex. It is possible that the SEP indicators selected for this study are not fully representative of the stress exposures that African Americans encounter, or of the resources that African Americans possess that protect them against the development of depression. Thus, it may be advantageous to investigate the effects of financial stressors, as well as neighborhood-level socioeconomic resources, in the prediction of depression among African Americans. Future work should also explore how racial discrimination, a prominent stressor, and an important predictor of depression among African Americans within the public health literature [22, 37, 39, 41], affects the relationship between SEP and depression. Exposure to racial discrimination is related to increased odds of depression [22], and Hudson et al. [17] found that experiences of racial discrimination attenuate the relationship between SEP and depression among African American men [17].

While the findings presented here indicate that economic resources are not the sole answer to depression among African Americans, they do call for researchers to pay close attention to the role that gender plays, including how stress exposure and stress effects vary by gender, in the 
prediction of depression among African Americans. There is a need for continued investigation of the cultural and social factors that African Americans experience throughout the life course that translate to diminished health status. Additionally, episodes of depression that occur in early adulthood, as well as those in childhood and adolescence, likely influence accumulation of SEP and affect risk of depression later in life and deserve further attention in future studies. The findings presented here and the research directions outlined are important for developing policies that not only reduce the socioeconomic disparities that negatively affect the mental health of African Americans, but also address the unique social stressors that African Americans may encounter across all levels of SEP.

Acknowledgments This work was supported by the National Institute of Mental Health (NIMH; grants U01-MH577165; R01MH068804-04), with supplemental support from the Office of Behavioral and Social Science Research at the National Institutes of Health, the University of Michigan, and the Center for Research on Ethnicity, Culture and Health funded through the National Institute of General Medical Sciences (5R25GM058641-10). Additional support was provided by the Kellogg Health Scholars Program and the University of California, San Francisco, Center on Research in Social Disparities. We are also thankful to Dr. Nancy Adler and Karen Simpkins for her helpful editorial feedback as well as the anonymous reviewers.

Open Access This article is distributed under the terms of the Creative Commons Attribution Noncommercial License which permits any noncommercial use, distribution, and reproduction in any medium, provided the original author(s) and source are credited.

\section{References}

1. Blazer DG, Kessler RC, McGonagle KA, Swartz MS (1994) The prevalence and distribution of major depression in a national community sample: the National Comorbidity Survey. Am J Psychiatry 151:979-986

2. Breslau J, Aguilar-Gaxiola S, Kendler KS, Su M, Williams D, Kessler R (2006) Specifying race-ethnic differences in risk for psychiatric disorder in a USA national sample. Psychol Med 36:57-68

3. Breslau N, Schultz L, Peterson E (1995) Sex differences in depression: a role for preexisting anxiety. Psychiatry Res 58:1-12

4. Cawthorne A (2009) Weathering the storm: Black Men in the Recession. Center for American Progress, Washington

5. Cole ER, Omari SR (2003) Race, class and the dilemmas of upward mobility for African Americans. J Soc Issues 59:785-802

6. Dohrenwend BP, Levav I, Shrout PE et al (1992) Socioeconomic status and psychiatric disorders: the causation-selection issue. Science 255:946-952

7. Ennis NE, Hobfoll SE, Schroder KEE (2000) Money doesn't talk, it swears: how economic stress and resistance resources impact inner-city women's depressive mood. Am J Community Psychol 28(2):149-173

8. Farmer MM, Ferraro KF (2005) Are racial disparities in health conditional on socioeconomic status? Soc Sci Med 60:191-204
9. Fincham FD, Beach SRH, Gordon TH, Osborne LN (1997) Marital satisfaction and depression: different causal relationships for men and women? Psychol Sci 8:351-357

10. Forman TA (2003) The social psychological costs of racial segmentation in the workplace: a study of African Americans' wellbeing. J Health Soc Behav 44:332-352

11. Gavin AR, Walton E, Chae DH, Alegria M, Jackson JS, Takeuchi D (2009) The associations between socio-economic status and major depressive disorder among Blacks, Latinos, Asians and non-Hispanic Whites: findings from the Collaborative Psychiatric Epidemiology Studies. Psychol Med 40(1):51-61

12. Hardaway CR, McLoyd VC (2009) Escaping poverty and securing middle class status: how race and socioeconomic status shape mobility prospects for African Americans during the transition to adulthood. J Youth Adolesc 38:242

13. Harrington R, Fudge H, Rutter M, Pickles A, Hill J (1990) Adult outcomes of childhood and adolescent depression: I. Psychiatric status. Arch Gen Psychiatry 47:465-473

14. Heeringa SG, Wagner J, Torres M, Duan NH, Adams T, Berglund P (2004) Sample designs and sampling methods for the Collaborative Psychiatric Epidemiology Studies (CPES). Int J Methods Psychiatr Res 13:221-240

15. Heflin CM, Patillo M (2002) Crossing class boundaries: race, siblings, and socioeconomic heterogeneity. Joint Center for Poverty Research, Northwestern University/University of Chicago, Chicago

16. Higginbotham E, Weber L (1992) Moving up with kin and community: upward social mobility for black and white women. Gend Soc 6:416-440

17. Hudson DL, Neighbors HW, Geronomus AT, Yang J, Jackson JS (2010) Examining the effects of socioeconomic position and racial discrimination upon depression among African Americans (under review)

18. Jackson JS, Neighbors HW, Nesse RM, Trierweiler SJ, Torres M (2004) Methodological innovations in the National Survey of American Life. Int J Methods Psychiatr Res 13:289-298

19. Jackson JS, Torres M, Caldwell CH, Neighbors HW, Nesse RM, Taylor RJ, Trierweiler SJ, Williams DR (2004) The National Survey of American Life: a study of racial, ethnic and cultural influences on mental disorders and mental health. Int J Methods Psychiatr Res 13:196

20. Kawachi I, Adler NE, Dow WH (2010) Money, schooling, and health: mechanisms and causal evidence. Ann N Y Acad Sci 1186:56-68

21. Keister LA, Moller S (2000) Wealth inequality in the United States. Annu Rev Soc 26:63-81

22. Kessler R, Mickelson K, Williams D (1999) The prevalence, distribution, and mental health correlates of perceived discrimination in the United States. J Health Soc Behav 40:208-230

23. Kessler RC, Chiu WT, Demler O, Walters EE (2005) Prevalence, severity, and comorbidity of 12-month DSM-IV disorders in the national comorbidity survey replication. Arch Gen Psychiatry 62:617-627

24. Kessler RC, McGonagle KA, Swartz M, Blazer DG, Nelson CB (1993) Sex and depression in the National Comorbidity Survey I: Lifetime prevalence, chronicity, and recurrence. J Affect Disord 29:85-96

25. Kessler RC, Uston TB (2004) The World Mental Health (WMH) survey initiative version of the World Health Organization (WHO) composite international diagnostic interview (CIDI). Int J Methods Psychiatr Res 13:93-121

26. Leach L, Christensen H, Mackinnon A, Windsor T, Butterworth P (2008) Gender differences in depression and anxiety across the adult lifespan: the role of psychosocial mediators. Soc Psychiatry Psychiatr Epidemiol 43:983-998 
27. Muntaner C, Eaton WW, Diala C, Kessler RC, Sorlie PD (1998) Social class, assets, organizational control and the prevalence of common groups of psychiatric disorders. Soc Sci Med 47:2043-2053

28. Murphy JM, Olivier DC, Monson RR, Sobol AM, Federman EB, Leighton AH (1991) Depression and anxiety in relation to social status: a prospective epidemiologic study. Arch Gen Psychiatry 48:223-229

29. Neckerman K, Carter P, Lee J (1999) Segmented assimilation and minority cultures of mobility. Ethn racial stud 22:945-965

30. Nolen-Hoeksema S (2001) Gender differences in depression. Curr Dir Psychol Sci 10:173-176

31. Pearson JA (2008) Can't buy me whiteness. Du Bois Rev Soc Sci Res Race 5:27

32. Piccinelli M, Wilkinson G (2000) Gender differences in depression: critical review. Br J Psychiatry 177:486-492

33. Rodriguez E, Allen JA, Frongillo EA Jr, Chandra P (1999) Unemployment, depression, and health: a look at the AfricanAmerican community. J Epidemiol Community Health 53:335

34. Simning A, van Wijngaarden E, Conwell Y (2010) Anxiety, mood, and substance use disorders in United States AfricanAmerican public housing residents. Soc Psychiatry Psychiatr Epidemiol [Epub ahead of print]

35. Stansfeld S, Clark C, Rodgers B, Caldwell T, Power C (2010) Repeated exposure to socioeconomic disadvantage and health selection as life course pathways to mid-life depressive and anxiety disorders. Soc Psychiatry Psychiatr Epidemiol [Epub ahead of print]
36. Walsemann K, Geronimus A, Gee G (2008) Accumulating disadvantage over the life course. Res aging 30:169

37. Williams DR, Chung A-M (1997) Racism and health. In: Gibson R, JS J (eds) Health in Black America. Sage Publications, Thousand Oaks

38. Williams DR, Gonzalez HM, Neighbors H, Nesse R, Abelson JM, Sweetman J, Jackson JS (2007) Prevalence and distribution of major depressive disorder in African Americans, Caribbean blacks, and non-Hispanic whites: results from the National Survey of American Life. Arch Gen Psychiatry 64:305-315

39. Williams DR, Neighbors HW, Jackson JS (2003) Racial/ethnic discrimination and health: findings from community studies. Am J Public Health 93:200-208

40. Williams DR, Takeuchi D, Adair R (1992) Socioeconomic status and psychiatric disorder and African Americans and Whites. Soc Forces 71:179-194

41. Williams DR, Yu Y, Jackson JS, Anderson NB (1997) Racial differences in physical and mental health: socioeconomic status, stress and discrimination. J Health Psychol 2:335-351

42. Wittchen HU, KR C, Ustun TB (2001) Properties of the Composite International Diagnostic Interview (CIDI) for measuring mental health outcome. In: Thornicroft G, Tansella M (eds) Mental health outcome measures, pp 212-227

43. Yuan YC (2001) Multiple imputation for missing data: concepts and new development. SAS/STAT 82, Cary 